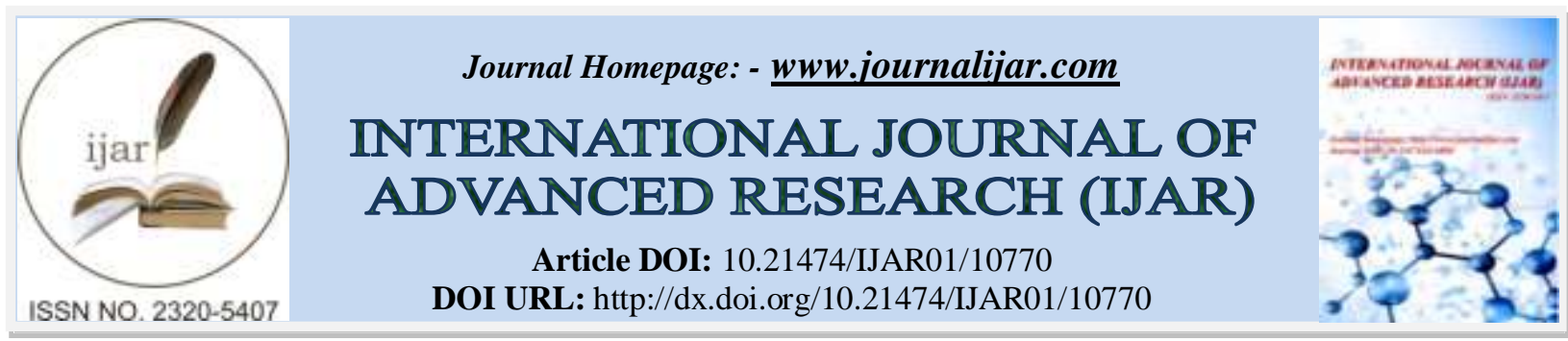

RESEARCH ARTICLE

\title{
KNOWLEDGE AND AWARENESS REGARDING INFANT ORAL HEALTH CARE AMONGST ANGANWADI WORKERS UNDER ICDS PROGRAMME IN DISTRICT BARAMULLA, JAMMU AND KASHMIR, INDIA
}

\section{Dr. Ambreena Khurshid ${ }^{1}$, Dr. Abhishek Dindsa ${ }^{2}$, Dr. Pooja Goel ${ }^{1}$, Dr. Gurpreet Kour ${ }^{3}$, Dr. Avijit Avasthi ${ }^{4}$, Dr. Nadia Irshad ${ }^{5}$ and Dr. Yawar ${ }^{6}$}

1. PG Student Department of Pedodontics and Preventive Dentistry Swami Devi Dyal Hospital And Dental College Barwala Panchkula Haryana.

2. Professor Department Pedodontics and Preventive Dentistry Swami Devi Dyal Hospital And Dental College Barwala Panchkula Haryana.

3. Senior Lecturer Department Pedodontics and Preventive Dentistry Swami Devi Dyal Hospital And Dental College Barwala Panchkula Haryana.

4. Lecturer, Bhojia Dental College, Baddi, Himachal Pradesh.

5. PG Student Department Pedodontics and Preventive Dentistry, BRS Dental College.

6. BDS Student Swami Devi Dyal Hospital And Dental College Barwala Panchkula Haryana.

\section{Manuscript Info}

.1........................

Manuscript History

Received: 07 February 2020

Final Accepted: 10 March 2020

Published: April 2020

Key words:-

Anganwadi Workers, Awareness, Infant Oral Health, Knowledge

\section{Abstract}

Objectives : Anganwadi workers (AWWs) provides a package of health services to mothers and infants, thereby playing a significant role in enhancement of community health. The present study aimed to assess knowledge and awareness regarding infant oral heath care amongst anganwadi workers under Integrated child development service programme in district Baramulla, Jammu and Kashmir India.

Methods: A questionnaire based survey consisting of 10 questions regarding knowledge and awareness regarding infant oral health care was conducted among 105 anganwadi workers of boniyar block district baramulla Jammu \& Kashmir, India.

Results: Of the 105 participants, only $22.16 \%$ AWWs knew that baby's mouth should be immediately after mother's feed. $51.42 \%$ AWWs reported that cleaning of the oral cavity should be done with soft cloth. 11.4\% AWWs were aware that maximum breast feeding should be recommended for 18 months. $71.4 \%$ AWWs replied that milk tooth should be saved.

Conclusion: Our study concluded that AWWs posses knowledge and awareness about infant oral health care to some extend. However, there is strong need to conduct periodic health programs to updgrade the knowledge and awareness of AWWs related to infant oral health care .

Copy Right, IJAR, 2020,. All rights reserved.

\section{Corresponding Author:- Dr. Pooja goel}

Address:- PG Student Department of Pedodontics and Preventive Dentistry Swami Devi Dyal Hospital And Dental College Barwala Panchkula Haryana. 


\section{Introduction:-}

Oral health is an indispensable and integral component of children's overall health. The American Academy of Pediatric Dentistry (AAPD) recognizes that infant oral health is one of the foundations upon which preventable education and dental care must be built to enhance the opportunity for a lifetime, free from preventable oral diseases.

In a developing country like India the main emphasis was on prevention of various systemic diseases but off lately now the attention is being paid on oral prevention of various oral diseases and oral hygiene measures.. For this purpose anganwadi workers are being trained on infant oral health and they also create awareness amongst parents about healthy oral practices in children like correct brushing technique and hand washing through non formal education methods. Monthly meeting of mothers at anganwadis provide pathway for disseminating health education to mothers regarding breast feeding, immunization, safe delivery practices, prenatal and post natal care, growth monitoring, supplementary nutrition etc. Educating anganwadi workers regarding infant oral health will produce ripple effect of knowledge and awareness among mothers in the community which in turn can act as practically effective paradigm for developing countries like India where infant oral health care is not a priority in the primary health care as yet.

Anganwadi worker is the principal worker in the integrated child development services project in India The ICDS program was launched in india on $2^{\text {nd }}$ October 1975 , in response to the challenge of meeting the holistic needs of the child. In Jammu and Kashmir ICDS programme started in the year 1985 with the aim of preventing undernutrition in children upto three years of age, adressing pregnant and breastfeeding mothers, extending from the centre to family and community based approaches.

It is widely acknowledged that the young child is most vulnerable to malnutrition, morbidity, resultant disability and mortality. Today ICDS is one of the world's largest and most unique outreach programmes for children.

The aim of this study was to evaluate knowledge and awareness regarding infant oral health care amongst anganwadi workers under ICDS programme in district Baramulla, Jammu and Kashmir.

\section{Materials \& Methods:-}

Baramulla district is located in northern area of Indian UT of Jammu and Kashmir (J\&K) . The total area of Baramulla district is $122 \mathrm{~km}^{2}$ and total population is 1008039 as per 2011 census. This district is divided into 12 blocks (Baramulla, Pattan, Sopore, Rafiabad, Uri, Tangmarg, Kunzer, Wagoora, Singhpora, Narwah, Rohama and Boniyar). All the required and relevant information regarding number of anganwadi centers was obtained from state mission directorate office Jammu and Kashmir. As per their record, there were about 2425 anganwadi centers distributed over these blocks of district Baramulla with single anganwadi worker in each center with minimum qualification of $8^{\text {th }}$ standard. .

The study proposal was discussed with child development project officer Baramulla J \& K. After explaining the purpose of the study clearly to Child development project officer (CDPO) the written informed consent was obtained from the concerned department( Fig no.1). All the necessary data was collected regarding the anganwadi workers working in district Baramulla. An official monthly meeting was conducted in month of September 2018 in CDPO office where all district anganwadi workers gathered. Randomised controlled clinical trial was carried out and sample was selected by choosing one block .

There were about 155 anganwadi workers working in the Boniyar block. Participation information and the intent of the study was circulated among anganwadi workers in the in the regional language kashmiri . Written informed consent was obtained from the anganwadi workers who were willing to participate in the study. Out of 155 workers 125 were present and out of them 105 anganwadi workers participated in the study.

The study was a descriptive, cross-sectional questionnaire survey. A specially designed questionnaire consisting of 10 questions addressing knowledge and awareness regarding infant oral health care among anganwadi workers was put together (Table 1).

1What is appropriate time to clean mouth of child after birth?

a) Immediately after birth when mother feeds baby b) After 6 monthsc) when weaning has started d) Dnt Know 
2) What should be used for cleaning of teeth?

a) Finger brush b) Soft cloth c) Finger d) no need

3) When does first tooth erupt in the oral cavity?

a) 3 month b) 6 months c) 12 months d) Don't know

4) What according to you should be ideal time for first dental visit?

a) 6months b) 1 year c) 2 year d) Whenever child complains of pain

5) What should be maximum duration of breast feeding?

a) At child's will b) 12 months c) 18 months d) 24 months

6) Is there any deleterious effect of over and under feeding on oro facial structures?

a) Yes b) No c) May be d) Don't know

7) What is the appropriate time to start introduction of semisolid food in diet of child?a

a) 2-3 months b) 6 months c) year d) Don 't know

8) In case it is medically advised how often pacifier should be replaced?

a) 2 times per month b) Once a month c) Once in 3 months d) No need

9) If any problem should should milk teeth be treated or not?

a) Yes b) No

10) Does sticky and sugary food cause decay of teeth?

a)Yes b) No c) May be d) Don 't know

The questionnaire was constructed in simple english and was later translated into kashmiri for easy comprehension of the anganwadi workers. Further, the questionnaire was back translated into english to check for any inconsistencies between the translated form followed by filling up of questionnaire by the participants.

The collected data was compiled, tabulated and subjected to statistical analysis.

\section{Results:-}

A total of 105 anganwadi workers responded to questionnaire. Out of 105 anganwadi workers 99 were females $(95 \%)$ and only 6 were males (5\%) (fig. 1$)$.

Majority of them had upto 10 years of experience $(47.6 \%), 15$ years of experience in $33.3 \%, 20$ years of experience in $14.3 \%$ and only 5 years experience in $4.8 \%$ of anganwadi workers( fig.2).

Figure 3 shows that $28.6 . \%$ of anganwadi worker (30 out of 105) had minimum qualification upto matric, $47.6 \%$ had qualification upto $8^{\text {th }}$ standard(50 out of 105), $19 \%$ had qualification of higher secondary school (20 out of 105 and only $4.8 \%$ had qualification of bachelors degree (5 out of 105 )

Figure 4 reveals that $61.90 \%$ (65 out of 105) anganwadi workers were in the age group of $41-50$ years ,19.04\% (20 out of 105) of anganwadi workers were in age range between 51-60 years, $14.28 \%$ (15 out of 105 ) of anganwadi workers were in age range of 31-40 yrs and only 4.76\% ( 5 out 105) anganwadi workers were in the age group of 20-30 years.

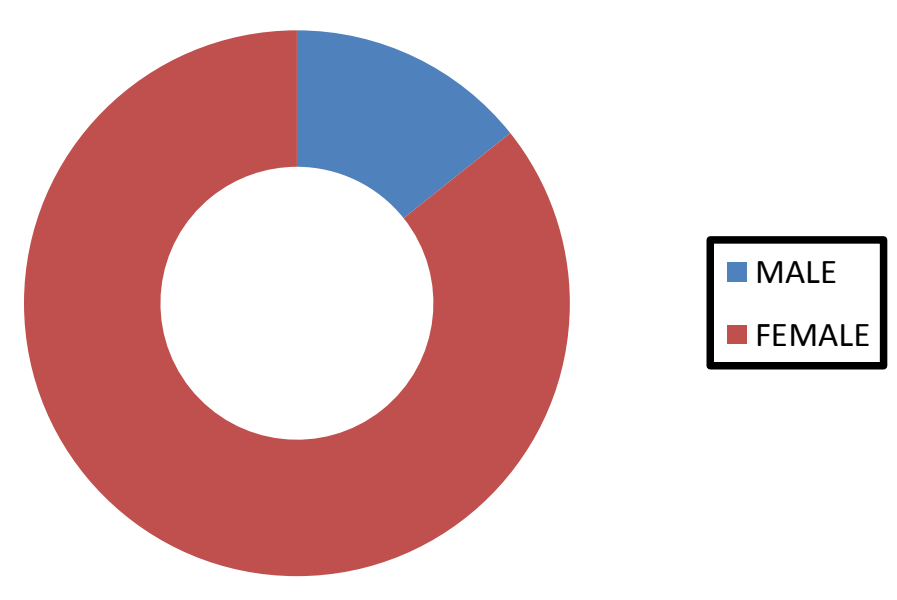

Fig 1:- Distribution of anganwadi workers according to gender. 


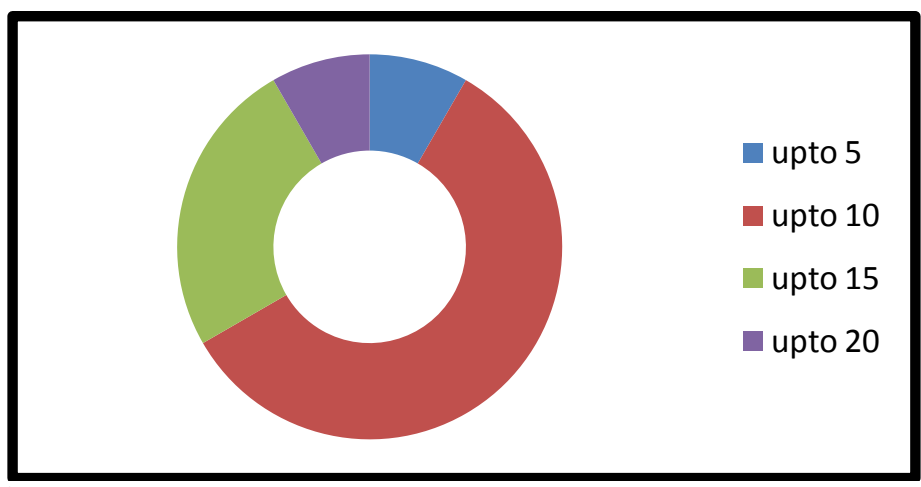

Fig 2:- Distribution of anganwadi workers according to years of experience.

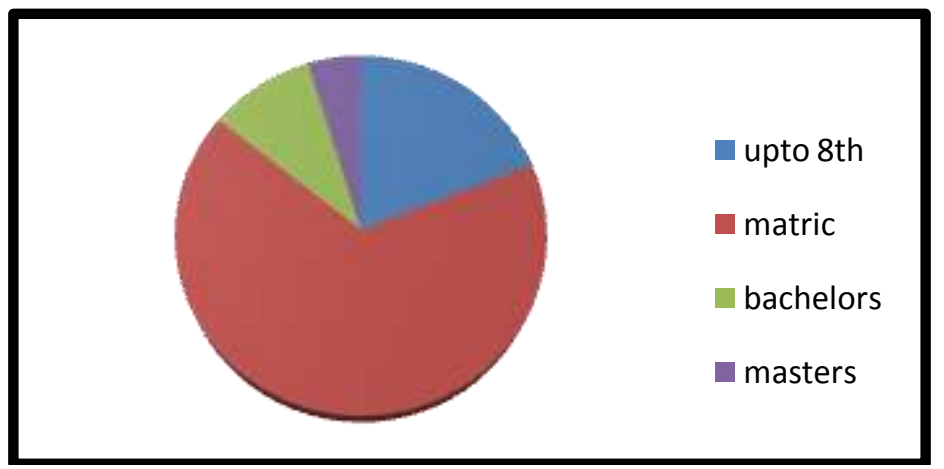

Fig 3:- Distribution of anganwadi workers according to qualification.

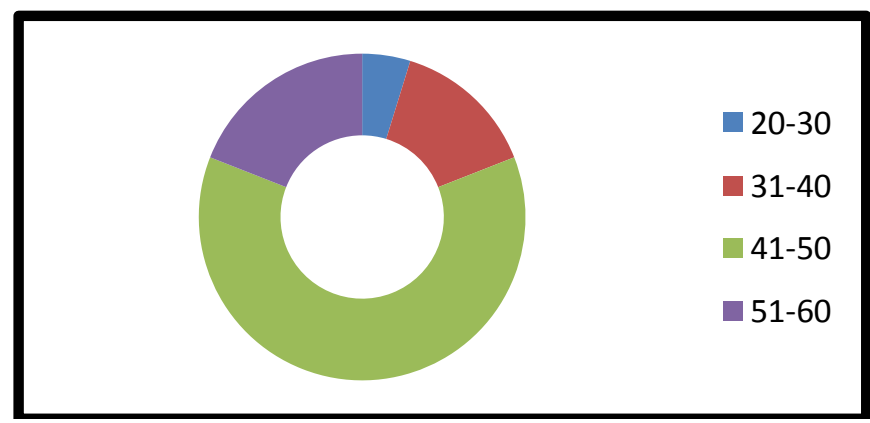

Fig 4:- Distribution of anganwadi workers according to age.

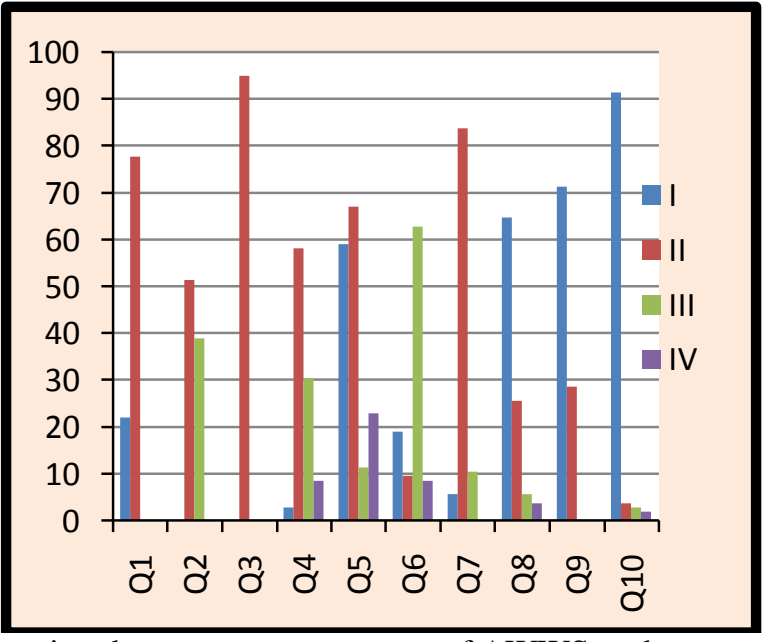

Fig 5:- denoting the percentage response of AWWS to the questionnaire. 


\section{Discussion:-}

Infant oral health care should be given prime importance as it deterrnines oral health status of the future generations. Good health is a major resource for social, economic and personal development. For optimal oral health, oral hygiene habits should be instilled at a very young age itself. Poor oral health can have many adverse effect on overall quality of life, it can increase the risk to general health and can also compromise chewing and eating abilities and which inturn can effect the nutritional intake of an individual and overall growth of the child.

A randomized controlled questionnaire based study with 105 anganwadi workers of district Baramulla were recruited in the present study in order to assess the existing knowledge and awareness regarding infant oral health related factors so that appropriate knowledge and measures could be implemented in order to develop foundation for healthy growth and development of child during infancy.

There were about 150 anganwadi workers in district Baramulla in Indian state of Jammu and Kashmir. 105 AWWs participated in the study clearly indicating their positive outlook and interest with regard to the infant oral health.

The Preventive oral health measures must begin at the period of infancy so as to ensure optimum oral hygiene. An important aspect of oral health care is that oral hygiene practices should begin in pre-dentate stage only. Cleaning of child's oral cavity should begin before the eruption of teeth and tooth brushing is recommended as soon as first primary teeth erupts into the oral cavity ; usaully at the age of 6 months. According to the response of the present study, only $22.16 \%$ AWWs expressed the need for cleaning of infants oral cavity immediately after mother's feed as depicted by Graph 1 . These results were quite surprising for the investigator. This could be attributed to the lack of awareness of anganwadi workers regarding preventive oral health measures infants.

Similar findings have been found in a study by Chan et al.,8 where only $44 \%$ of the caregivers suggested that oral cavity of an infant should be cleaned even before the first tooth eruption.

$39.04 \%$ anganwadi workers responded that cleaning of gum pads should be done using finger while only $0.04 \%$ believed that gum pads should be cleaned with finger brush . $51.42 \%$ AWWs reported that cleaning of the oral cavity should be done with soft cloth. However the results were not consistent with the study conducted by Virdi M et $\mathrm{al}^{13}$ in 2011 who reported that only $17.9 \%$ caregivers recommended cleaning of gum pads with moist soft cloth.

Due to the lack of knowledge regarding the importance of primary teeth, people are usually ignorant about the age of eruption of first primary teeth. Surprisingly in the present studies when anganwadi workers were asked about the age of eruption of first primary teeth, majority of anganwadi workers i.e $95.07 \%$ of the AWWs had correct knowledge regarding the age at which first primary tooth erupts in oral cavity. This might due exchange of knowledge from one generation to other. In a study conducted by Mani et $\mathrm{al}^{12}$ on caretakers of children attending day care centers, $91.2 \%$ of the study subjects knew the eruption timming of the first primary tooth.

Only $2.9 \%$ of AWWs agreed that first dental visit should be carried out at the age of 6 months while majority of anganwadi workers believed that first dental visit should be done at one year of age. Kumari $\mathrm{R}$ et al ${ }^{9}(2006)$ conducted a study in Kerala and reported that only $40 \%$ of the respondents were aware of the fact that first dental visit should be carried out before the first birthday of the infant. In order to prevent dental problems, a child should visit the pediatric dentist when first milk tooth erupts , usually at 6 months of age and certainly not after his/ her first birthday.

11.4\% AWWs were aware that maximum breast feeding should be recommended for 18 months. 59\% responded that breastfeeding should continued as per childs will.

Breastfeeding the infant helps the child maintain positive jaw growth patterns, maintain good oral hygiene and maintain cavity free environment. In the present study, Only $19.04 \%$ knew that over and under feeding was associated with deleterious effect such as early childhood caries, malocclusion, abnormal orofacial habit, respiratory disturbance, crowding, spacing, open bite and retained infantile swallowing. Mani SA et al ${ }^{12}$ suggested that only $26.5 \%$ (2010) of the pediatricians strongly agreed to the fact that frequent and prolonged breast / bottle feeding is associated with dental decay. 
Primary teeth plays a very significant role in mastication, esthetics, phonetics and also acts as space maintainer . Primary teeth are a determining factor in the development of occlusion. They act as valuable gift to the child. Pain and swelling due to diseased primary teeth can cause discomfort to the child., reduced masticatory efficacy , improper nutrition, scanty growth and development, soft diet preference and in turn increases risk of dental caries. Decayed teeth may also ruin the beautiful smile of the child there by causing both physiological as well as pschyological impact and in turn causing negative impact on self esteem and confidence of the child patient. When the anganwadi workers were asked whether the milk teeth should conserved or not , 71.4\% AWWs replied that milk tooth should be saved. This study was contradictory to the study conducted by Poornima et al ${ }^{11}, 64.7 \%$ of the AWWs of Mysore city agreed that there is no need to take care of milk teeth because they will fall after some time.

About 91.4\% AWWs knew that sugary and sticky food is associated with dental decay in comparison to the study conducted by Mani et al ${ }^{12}$ where $97 \%$ of caretakers believed that dental decay is associated with intake of sugary and sticky food. After conducting the survey all the queries were answered by the interviewer.

\section{Conclusion:-}

Anganwadi worker have a crucial role to play in the health care system. The investigator is of the firm opinion and believes that there is need of upgrading the knowledge and awareness among AWWs regarding oral health by conducting periodic oral health education programs so that correct knowledge and positive attitude regarding infant oral health care can be spread to the masses in order to reduce the burden of treating future oral diseases, thereby bringing physiological and pschylogical benefit to child .

More over the authorities must include the topic of infant oral health care in curriculum of freshly recruited anganwadi workers which seems to be most feasible and practical measure to prevent oral diseases in future.

\section{Conflict of interest:}

Nil

\section{References:-}

1. Arora R, Singh S, Malik S. To evaluate the awareness of infant oral health care in anganwadi workers of Udaipur city. IOSR Journal of Dental and Medical Sciences 2016; 15(4): 116-120.

2. Gambhir RS, Anand S, Gupta T, Singh A, Kahlon H, Kaur A. Knowledge and awareness regarding oral health among anganwadi workers in India: A systematic review. Journal of Indian Association of Public Health Dentistry 2016; 14(2): 231-236.

3. Nair MKC, Renjit M, Siju KE, Leena ML, George B, Kumar GS. Effectiveness of a community oral health awareness program. Indian Pediatrics 2009; 46:86-90.

4. Basavaraj SP, Basha S, Kumar PGN, Manjunath PG, Hirekalmath SV, Imranulla M. Knowledge of early childhood caries among anganwadi workers in davangere city, India. International Journal of Oral Health Sciences 2013; 3(2):75-78.

5. Ahmed R, Kaul R, Kaul V, Rajan S. Knowledge and attitude of anganwadi workers regarding oral health of children in ICDS project Dansal, Jammu and Kashmir. International Journal of Oral Health Dentistry 2018;4(1): 27-30.

6. Kakodkar P, Matsyapal K, Ratnani N, Agrawal R. Anganwadi workers as oral health guides : An interventional Study. Journal of Dental Research and Scientific Development 2015;2(2):33-37.

7. Petersen PE. The World Oral Health Report. Continuous improvement of oral health in the $21^{\text {ST }}$ century- the approach of the WHO Global Oral Health Programme. WHO/NMH/NPH/ORH/03.2

8. Chan SC, Tsai JS, King NM. Feeding andoral hygiene habits of preschool children in Hong Kong and their caregivers dental knowledge and attitudes.Int J Paediatr Dent 2002;12:322-31.

9. Kumari RN, Sheela S, Sardana PN. Knowledge and attitude on infant oral health among graduating medical students in Kerala. JISPPD 2006:173-176.

10. Kranz AM, Rozier RG, Zeldin LP, Preisser JS. Oral health activities of early head start teachers directed toward children and parents. J Public Health Dent 2011;71:161-9.

11. Poornima K, Reddy CV, Shivakumar BN, Vidya M. A study to assess the knowledge, attitude and practices towards oral health among anganwadi workers of Mysore City. J Indian Assoc Public Health Dent 2011;18:167-70.

12. Mani SA, Aziz AA, John J, Ismail NM. Knowledge, attitude and practice of oral health promoting factors among caretakers of children attending day-care centers in KubangKerian, Malaysia: A preliminary study. J Indian Soc PedodPrev Dent 2010;28:78-83.

13. Virdi MS, Kaur M, Mittal SK. Paediatricians take on oral health care of children.International Journal of Pediatrics and Neonatology 2011;13(1):313-317. 